\title{
Editorial
}

\section{Moving Sustainability Forward: Contributions and Outcomes of the 3rd World Sustainability Forum}

\author{
Marc A. Rosen ${ }^{1}, *$ and Samanta La Russa ${ }^{2}$ \\ 1 Faculty of Engineering and Applied Science, University of Ontario Institute of Technology, 2000 \\ Simcoe Street North, Oshawa, Ontario L1H 7K4, Canada \\ 2 MDPI AG, Klybeckstrasse 64, CH-4057 Basel, Switzerland; E-Mail: larussa@ mdpi.com \\ * Author to whom correspondence should be addressed; E-Mail: Marc.Rosen@uoit.ca; \\ Tel.: +1-905-721-8668; Fax: +1-905-721-3370.
}

Received: 16 January 2014 / Accepted: 16 January 2014 / Published: 21 January 2014

\section{Introduction and Background}

The 3rd edition of the World Sustainability Forum (WSF) was again a success. This electronic conference, held from 1-30 November 2013 on the platform sciforum.net, attracted more than 160 authors from all over the world, who contributed over 50 papers to the multidisciplinary sections comprising the Forum.

This brief report sums up the contributions and discussions generated at the 3rd World Sustainability Forum, and provides an overview of the Forum concept, the presented topical sections and a summary about the output of the discussion. Already aiming for the 4th edition, we include an outlook for the upcoming World Sustainability Forum in 2014.

\section{World Sustainability Forum}

Given today's hectic working schedule of academics, it is becoming increasingly challenging for scholars to attend and follow international conferences, without detracting from their other activities. The internet platform, sciforum.net, hosts many internationally held scientific electronic conferences. The World Sustainability Forum was held for the 3rd time on sciforum.net facilitating participation of many scholars and practitioners, allowing them to present and learn of the latest work in sustainability and exchange knowledge amongst scientific peers concerned with the discipline. This form of conference seems to be becoming more and more attractive since the concept of e-conferences provides the flexibility that allows each participant to arrange her/his schedule and, above all, it avoids concerns of travel expenditures. The rapid and direct communication, allowing full flexibility of 
participants, is especially useful for a conference on sustainability. The 3rd WSF was aimed at encouraging and developing critical discussions, and resulted in presented research papers and applications of both theoretical as well as practical investigations in this multidisciplinary scientific field.

\section{Results and Discussion}

\subsection{Section Descriptions}

This year's contributions were centered on similar topical sections as presented in earlier editions, highlighting the importance of sustainability and sustainable development, and on the interplay of these key issues:
A. Environmental Sustainability
B. Corporate Sustainability Strategy
C. Social Values for a Sustainable Economy
D. Energy Efficiency and Renewable Energy Sources
E. Sustainable Urban Development
F. Sustainable Development Policy, Practice and Education
G. Sustainability Entrepreneurship and Sustainability Innovation
H. Sustainable Agriculture and Sustainable Management of Land and Biodiversity
I. Related Topics

In Section A, Environmental Sustainability, 19 papers were presented, dealing with life-cycle assessment analysis of humans and nature among other environmental topics. The section also addressed resources as well as issues like sustainable food systems, tourism and its approach to being sustainable, and environmental topics from a socio-economic point of view. All papers stress that today's sustainability discussion is driven by the keyword of 'challenge', and thus overlaps with papers from other sections. Papers from this section are available online at http://sciforum.net/conference/wsf3/a.

Section B, Corporate Sustainability Strategy, presented papers, including some which provided reviews of self-directed management, and assessments of how the involvement of local stakeholders can enhance the sustainability of a national project. This section's papers are available online at http://sciforum.net/conference/wsf3/b.

Topics discussed in Section C, Social Values for a Sustainable Economy, were concerned with the social values within sustainable community practices. Various case studies were presented, highlighting the various impacts of social values. These papers are available online at http://sciforum.net/conference/wsf3/c.

In Section D, Energy Efficiency and Renewable Energy Sources, ten papers were presented which concretely dealt with sustainable and renewable energy and efficiency issues (e.g., analyses of waste heat recovery and energy efficient buildings), as well as alternative and less environmentally intrusive energy forms such as solar energy, geothermal energy and alternative fuels, such as bioethanol. The papers provided critical reviews as well as novel ideas and approaches, which were also included in the discussion during the WSF3. This section's papers are available online at http://sciforum.net/conference/wsf3/d. 
Six papers were published in Section E, Sustainable Urban Development. The presented papers discussed issues regarding smart and sustainable urban city design, local energy supply methods and domestic water use systems. Section E papers are available online at http://sciforum.net/conference/wsf3/e.

Section F, Sustainable Development Policy, Practice and Education, presented nine papers discussing various topics on current ideas and projects in sustainable development practices. These included a critical review of the Latrine Program in Nepal, and how a country like Nepal deals with its rapid development from a sustainability-related perspective. Others discussed the centrality of the sustainable well-being of humans, and what kind of barriers exist when it comes to universities and sustainability, from a student's perspective. Papers for this section are available online at http://www.sciforum.net/conference/wsf3/f.

In Section G, Sustainable Entrepreneurship and Sustainability Innovation, papers discussed opportunities and challenges relating to the development of sustainable innovations. The university, as an economic driver of technological innovation, was a focus, as was as a project in Tongan schools, where photovoltaic systems were installed in partnership with various Tongan parties. Papers for Section $\mathrm{G}$ are available online at http://www.sciforum.net/conference/wsf3/g.

Section H, Sustainable Agriculture and Sustainable Management of Land and Biodiversity, focused on concrete practices when it comes to strategies and tools for sustainable agriculture and farming. The papers in Section $\mathrm{H}$ are available online at http://www.sciforum.net/conference/wsf3/h.

The Related Topics Section collected papers from various fields such as archaeology and sustainability in the Brazilian Amazon, as well as the linkage of sustainable consumption with sustainable healthcare and health consumer discourses.

\subsection{Further Material}

In addition to the papers presented on the conference web site, authors were invited to introduce their thoughts in a video presentation. Dr. Marc A. Rosen, the Chairman of the World Sustainability Forum and Editor-in-Chief of the journal Sustainability, recorded a keynote for the conference which was also made available online.

Discussions concerning conference papers and more general topics were carried out via a mailing list. This year's stimulating discussion was driven by keywords such as environment, resources and potential future scenarios. Participants shared their thoughts and concerns on future scenarios and argued about ideas and approaches. This discussion highlights again how multidisciplinary and conflicting it is to deal with 'sustainability' in general. The discussion has been made available online at http://www.sciforum.net/file/download/WSF3_Discussion.pdf.

\section{Conclusions}

The 3rd World Sustainability Forum has repeatedly shown how important it is to focus on issues related to sustainability. The Forum facilitated participants to examine, explore and critically engage themselves on issues and advances in sustainability; highlighted again that e-conferences are events which can make a difference and provide a highly beneficial complement to on-site conferences. 
In the 4th World Sustainability Forum, which will take place 1-30 November 2014, we want to implement an optimized way to encourage and further facilitate discussions and peer exchange. The Forum aims to continuously improve and attract more international researchers and practitioners from different disciplines. Interesting and productive debates will be included reporting advances in all areas of sustainability. The organizers aim to make the platform and the e-conferences more sustainablefor the present and for the future.

\section{Conflicts of Interest}

The authors declare no conflict of interest.

(C) 2014 by the authors; licensee MDPI, Basel, Switzerland. This article is an open access article distributed under the terms and conditions of the Creative Commons Attribution license (http://creativecommons.org/licenses/by/3.0/). 